\title{
Evidence of a founder effect for four cathepsin C gene mutations in Papillon-Lefèvre syndrome patients
} Y Zhang, T Lundgren, S Renvert, D N Tatakis, E Firatli, C Uygur, P S Hart, M C Gorry,
J J Marks, T C Hart

Department of Oral Biology, University of Pittsburgh School of Dental Medicine, 614 Salk Hall, 3501 Terrace Street, Pittsburgh, PA 15261, USA

Y Zhang

M C Gorry

J J Marks

T C Hart

Department of Periodontics, Loma Linda University, Loma Linda, CA 92354, USA

T Lundgren

D N Tatakis

Department of Health Sciences, Kristianstad University, Sweden

S Renvert

Department of Periodontology, University of Istanbul School of Dentistry,

Istanbul, Turkey E Firatli

C Uygur

Department of Human Genetics, University of Pittsburgh, Graduate School of Public

Health, Pittsburgh, PA 15261, USA

P S Hart

T C Hart

Correspondence to: Dr T C Hart,

hart@cpc.pitt.edu

Revised version received 27 November 2000 Accepted for publication 28 November 2000

\begin{abstract}
We describe a mutation and haplotype analysis of Papillon-Lefèvre syndrome probands that provides evidence of a founder effect for four separate cathepsin $\mathrm{C}$ mutations. A total of $\mathbf{2 5}$ different cathepsin C mutations have been reported in 32 families with Papillon-Lefèvre syndrome (PLS) and associated conditions. A characteristic of these findings is the diversity of different cathepsin $\mathrm{C}$ mutations that have been identified. To evaluate the generality of cathepsin C mutations, PLS probands representative of five reportedly unrelated Saudi Arabian families were evaluated by mutational and haplotype analyses. Sequence analysis identified two cathepsin C gene mutations: a novel exon 7 G300D mutation was found in the proband from one family, while probands from four families shared a common R272P mutation in exon 6. The R272P mutation has been previously reported in two other non-Saudi families. The presence of the R272P mutation in probands from these four Saudi families makes this the most frequently reported cathepsin $\mathrm{C}$ mutation. To distinguish between the presence of a possible founder effect or a mutational hot spot for the R272P mutation, we performed haplotype analysis using six novel DNA polymorphisms that span a $165 \mathrm{~kb}$ interval containing the cathepsin $\mathrm{C}$ gene. Results of haplotype analysis for genetic polymorphisms within and flanking the cathepsin C gene are consistent with inheritance of the R272P mutation "identical by descent" from a common ancestor in these four Saudi families. Haplotype analysis of multiple PLS probands homozygous for other cathepsin C mutations (W249X, Q286X, and T153I) also supports inheritance of each of these mutations from common ancestors. These data suggest that four of the more frequently reported cathepsin C mutations have been inherited from common ancestors and provide the first direct evidence for a founder effect for cathepsin $\mathrm{C}$ gene mutations in PLS. Identification of these six short tandem repeat polymorphisms that span the cathepsin $\mathrm{C}$ gene will permit haplotype analyses to determine other founder haplotypes of cathepsin C mutations in additional PLS families. (F Med Genet 2001;38:96-101)
\end{abstract}

Keywords: Papillon-Lefèvre syndrome; cathepsin C; founder effect; chromosome 11q14
Papillon-Lefèvre syndrome (PLS) is a type IV palmoplantar keratosis (PPK). ${ }^{12}$ While the palmoplantar keratodermas share some features of palmoplantar keratosis, they are aetiologically heterogeneous. PLS differs from other PPK by the presence of severe, early onset periodontitis. PLS (MIM 245000) is transmitted as an autosomal recessive trait, and an increased prevalence of parental consanguinity has been reported in PLS patients..$^{3-5}$ Although several different immunological findings have been reported in PLS affected subjects, these findings did not help to identify the underlying genetic defect. The genetic basis for most PLS cases appears to be mutations affecting both alleles of the cathepsin C gene (CTSC), located on chromosome $11 \mathrm{q} 14$. The majority of patients with PLS are reported to be homozygous for the same cathepsin $\mathrm{C}$ mutation. ${ }^{6-8}$ Given the increased prevalence of parental consanguinity in PLS affected subjects, this finding is not unexpected. Biochemical assays of cathepsin C indicate that CTSC mutations associated with PLS and related conditions dramatically reduce its enzymatic activity. Heterozygous carriers of the mutation have approximately $50 \%$ of enzymatic activity, while subjects in whom both cathepsin C alleles are mutated show less than $10 \%$ of normal activity in hydrolysis of the synthetic substrate glycylL-arginine-7-amino-4-methylcoumarin. ${ }^{7}$

A causative role for CTSC mutations in PLS has been established for most $(\sim 80 \%)$, but not all cases of PLS. Several PLS cases exist in which mutations of the coding regions of CTSC have not been identified, although several of these families are consistent with genetic linkage to the interval of chromosome $11 \mathrm{q} 14$ that contains the cathepsin $\mathrm{C}$ gene locus. ${ }^{8}$ While cathepsin $\mathrm{C}$ mutations have been identified in a range of ethnic groups, they have not been reported in PLS affected subjects from Saudi Arabia, even though PLS is well documented in this population. ${ }^{9-13}$ To determine the generality of cathepsin C mutations, five PLS probands from reportedly unrelated families were ascertained from a dental clinic in Saudi Arabia. These subjects presented for treatment of severe periodontitis associated with PLS.

\section{Methods and results}

Following informed consent, periodontal tissues were surgically resected. DNA was isolated using the QiaAmp blood DNA purification kit with modification. After homogenisation in phosphate balanced saline, gingival 


\section{Wild type}

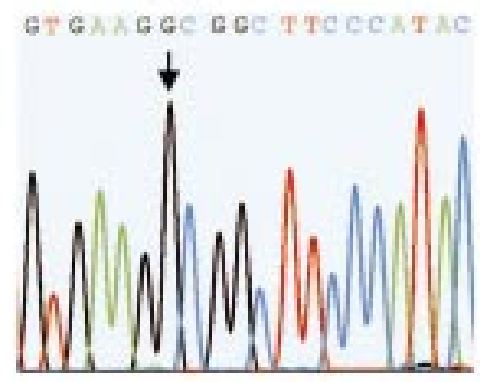

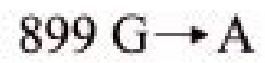

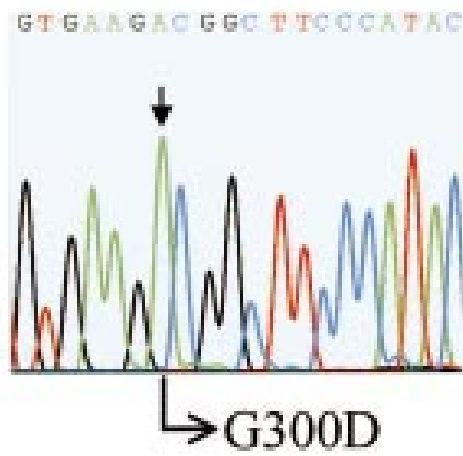

Figure 1 Novel mutation in CTSC. Sequencing of exon 7 showed a $G$ to $A$ transition at nucleotide 899 which results in substitution of glycine at position 300 by aspartic acid identified in proband $x 768$ from Saudi Arabia.

tissue was incubated in a solution of AL buffer (Qiagen Inc) and protease for two hours at $56^{\circ} \mathrm{C}$. All seven exons and associated splice site junctions of the cathepsin C gene were PCR amplified using oligonucleotide primers as previously described. ${ }^{7}$ Following amplification, PCR products were purified using a Qiagen PCR Clean-Up kit. The sense and antisense strands of each PCR product were directly sequenced on an ABI 310 Genetic Analyzer using four dye terminator chemistry. Sequencing data were automatically collected and analysed by the ABI Sequence Analysis software. DNA sequences were compared with CTSC genomic sequences in GenBank (GI1947070) using the BLAST search program. ${ }^{14}$ Intron-exon junctions were manually compared with the reported wild type CTSC consensus sequence. ${ }^{78}$ Sequence analysis of the CTSC gene in these probands identified a nucleotide 815 mutation ( $G$ to $C$ ) in exon 6, resulting in a R272P change in four of the probands, and a nucleotide 899 mutation ( $G$ to A) in exon 7 resulting in a novel G300D change in the fifth proband (fig 1).

The coding region of the CTSC gene spans approximately $46000 \mathrm{~kb}$, consisting of seven exons that code for a 463 amino acid polypeptide. To date, 25 different CTSC mutations have been identified in probands from 32 different families with PLS and related conditions. A remarkable finding has been the diversity of cathepsin $\mathrm{C}$ gene mutations identified. Mutations have been identified in exons 2-7 of the cathepsin $\mathrm{C}$ gene. ${ }^{78}$ While the majority of CTSC mutations reported have been unique, several have been reported in two or more families, including T153I (three families), Q286X (two families), G301S (two families), Y347C (two families), R339C (three families), and W429X (three families). ${ }^{78}$ The R272P mutation identified in four Saudi families in this report has also been previously reported in two additional families. ${ }^{78}$ In the homozygous state, the R272P CTSC mutation is associated with minimal enzymatic activity of cathepsin C. ${ }^{8}$ The presence of the R272P mutation in six PLS families makes this the most frequently reported CTSC mutation, occurring in approximately $15 \%$ of PLS probands. Several possibilities exist for the relatively high fre-

quency of CTSC R272P mutations, including a possible mutational hot spot or a founder effect for this mutation. Haplotype studies could help to determine if a specific mutation appears to occur on a common genetic background suggesting it has been inherited from a common ancestor, or if the shared mutation appears to have arisen independently multiple times. Unfortunately, the available genetic polymorphisms that were used to localise the gene responsible for PLS to chromosome $11 \mathrm{q} 14$ are not adequate for such haplotyping studies. The contiguous DNA sequence is not known for the genetic interval spanning the STRP markers used in linkage analyses for PLS, and the distance between these markers and their exact order is not known with certainty. ${ }^{15-17}$ Additionally, current physical maps of the interval place the CTSC gene at three possible locations relative to STRP loci, in a $4.5 \mathrm{cM}$ interval flanked by D11S1887 and D11S1311 (Genbridge 4 Radiation Hybrid map; www.ncbi.nlm.nih.gov/genemap99). In previous studies we have placed the CTSC gene within a $3 \mathrm{cM}$ interval flanked by D11S1367 and D11S931, but this localisation cannot be confirmed without a contiguous primary sequence of the interval. ${ }^{18}$ As a result, use of these STRPs to perform haplotype analyses is inadequate. This genetic interval is too large to make assumptions of inheritance of mutations "identical by descent" (IBD) for subjects who may be separated over many generations.

For the purposes of haplotype analyses, the most important interval is that containing and immediately spanning the CTSC gene. Using computational methods, we have identified and ordered fragments from 11 BACs to create a contig that contains the CTSC gene. Using the BLAST program algorithm, we searched the non-redundant human database and the high throughput genome sequence to identify a BAC clone (RP11-292E14) that contained sequence homology to the CTSC gene (AC011088). ${ }^{14}$ We then used the fragmented pieces of this BAC to identify additional BACs that shared $>95 \%$ sequence homology. With this strategy, we identified 10 additional fragmented BACs (listed in fig 2), which were then aligned and ordered using the Sequencher program (GeneCodes Corp). With this approach we were able to develop a BAC contig (fig 2), which spans $\sim 380000$ base pairs, containing the complete coding region as well as the immediate 5' promoter region and 3' UTR of the CTSC gene. In order to identify polymorphic loci for haplotyping, we screened this contig for short tandem repeat polymorphisms (STRPs) using the Tandem Repeat Finder at http://c3.biomath.mssm.edu/ trf.html. ${ }^{19}$ With this approach, we identified six novel STRPs that span the CTSC gene contig. Oligonucleotide primers flanking each STRP were designed using Oligo 4.0 based on the BAC contig fragments listed in fig 2 . Fluorescence labelled primers were used in the amplification of specific products. PCR products were detected by an ABI377 fluorescent sequencer and analysed by GENESCAN 2.1 (Applied Biosystems Inc). 
A

Figure 2 BAC contig spanning the CTSC gene. The BAC contig was constructed from $11 B A C$ clones as described in the text. Fragmented BACs which were incorporated into contig are: RP11-428B3 (Accession No AC009885) fragments 1, 2, 3, 4, and 6; RP11-114M5 (Accession No AC009927) fragments 2 and 3; complete RP11-292E14 (Accession No AC011088); RP11-334M8 (Accession No AC011629) fragments 3, 4, 5, 7, 8, 10, 12, 13, 14, 15, 16, 17, and 19; RP11-22C16 (Accession No AC018775) fragments 3, 7, 9, and 12; RP11-588K15 (Accession No AC023888) fragments 5 and 7; RP11-876F8 (Accession No AP000795) fragments 1, 5, 6, and 9; RP11-685B24 (Accession No AP001642) fragments 1, 2, 3, 4, 5, 7, and 8; RP11-113K4 (Accession No AP002362) fragments 1, 3, 4, 5, 6, 7, and 8; RP11-2544N1 (Accession No AP002497) fragments 2, 3, 5, 6, 7, 10, 11, 12, 14, 15, 16, 17, 20, 21, 22, 23, 24, and 25; and RP11-2232N20 (Accession No AP002510) fragments 1, 2, 4, 5, 6. (I) The BAC contig was first constructed as three overlapping fragments $(A, B$, and $C)$ as shown above the complete contig. The overlapped sequences of fragments $A$ and $B$ and $B$ and $C$ are shown in hatched boxes. The first nucleotide of the contig was considered to be No 1. (II) Location of novel STRP markers spanning the CTSC gene. Each of the STRP markers and the starting nucleotide number at the 5' end of the forward primer are shown. The location of the CTSC gene is shown in a box. (III) The genomic structure of the CTSC gene with intron distances drawn to scale and exons depicted as vertical lines. The 5' and 3' untranslated regions are shown as open boxes. A base pair scale (bp) is provided for each section.

The location of these STRP loci on the contig and their relation to the cathepsin $\mathrm{C}$ gene is shown in fig 2. Two loci, CTSC-01 and CTSC5', are in the region $5^{\prime}$ to the CTSC start codon, the CTSC-int3 locus is located within intron 3, and three loci, CTSC-3', CTSC-02, and CTSC-03, span an interval 3' to the gene. Oligonucleotide primers and annealing temperatures used to amplify each of these STRPs are given in table 1 .

The six novel STRPs identified span the CTSC gene and are localised within an interval of less than $164 \mathrm{~kb}$. The expected recombination frequency across this interval is $<0.002$. Existing genetic maps that include genetic markers used in linkage studies to localise the PLS gene locus (D11S931, D11S1311, D11S1358, D11S1887) span $4.5 \mathrm{cM}$ and do not precisely localise the cathepsin $\mathrm{C}$ locus (GenBridge 4). Using data obtained from the Human Genome Project Working Draft UCSC (http://genome.UCSC.edu), we estimated that the cathepsin C gene is $1187 \mathrm{~kb}$ from D11S1780 and $760 \mathrm{~kb}$ from D11S1367. The positions and distances of each of the six newly identified STRPs from the cathepsin C gene are known with certainty. The genetic distance between these new STRP markers is less than $10 \%$ of the distance between the closest markers used for linkage. None of the genetic markers used in previous PLS linkage studies are located on this BAC contig, indicating that they are outside this interval spanning the cathepsin C gene. These new STRPs are therefore much better markers to haplotype the interval and to evaluate evidence for a common or conserved genetic haplotype for PLS than any markers on existing physical maps of the interval. To determine allele frequencies for these novel STRP markers, we genotyped 112 chromosomes from unrelated, normal Turkish controls. PCR amplification of these STRPs was performed using $5 \mathrm{ng}$ of genomic DNA in a total volume of $7.5 \mu \mathrm{l}$ using TaqGold as described by the manufacturer for a total of 40 cycles with the annealing temperatures shown in table 1. Allele sizes and relative allele frequencies of each STRP observed for these controls are shown in table 1.

For haplotype analyses, we genotyped polymorphisms for the five Saudi PLS probands as well as an additional 22 PLS probands from different families, reported to be unrelated, for whom we have identified cathepsin C mutations. All subjects were genotyped for the six new STRPs that span the CTSC gene contig. They were all also genotyped for six DNA polymorphisms used in previous PLS linkage studies. Two markers, D11S937 and D11S4147, were from the Perkin Elmer $10 \mathrm{cM}$ linkage panel (Applied Biosystems Inc). The oligonucleotide primers for four other markers (D11S1887, D11S1780, D11S1367, and D11S1358) were redesigned using the Oligo 4.0 program, to permit more optimal PCR amplification. The modified oligonucleotide 
Table 1 STRP markers for human cathespin $C$ gene interval

\begin{tabular}{|c|c|c|c|c|c|}
\hline STRP & Location* & Allele size ( $b p)$ & Primer & Allele frequency & $T_{a n}\left({ }^{\circ} C\right)$ \\
\hline CTSC-01 & $8505-8811$ & $306-322$ & $\begin{array}{l}\text { F 5'-TAGGGCAAAATGTGTCTGAAGAGT-3'† } \\
\text { R 5'-TACCCATGAGATGGCTTTCATCAG-3' }\end{array}$ & $\begin{array}{l}306(.10) ; 308(.20) ; 310(.34) ; \\
312(.04) ; 314(.08) ; 318(.17) ; \\
320(.04) ; 322(.03) \ddagger\end{array}$ & 58 \\
\hline CTSC-5' & $57835-58180$ & $332-364$ & $\begin{array}{l}\text { F 5'-GCAGCACAGGACGGCTTTGAATAC-3' } \\
\text { R 5'-GATGGTGAAACCCTGTCTCTACTA-3' }\end{array}$ & $\begin{array}{l}332(.01) ; 334(.02) ; 336(.07) ; \\
338(.01) ; 340(.02) ; 342(.04) ; \\
344(.01) ; 346(.10) ; 348(.08) ; \\
350(.07) ; 352(.07) ; 354(.07) ; \\
356(.23) ; 358(.01) ; 360(.15) ; \\
362(.01) ; 364(.03) \ddagger\end{array}$ & 58 \\
\hline CTSC-int3 & $95935-96181$ & $239-251$ & $\begin{array}{l}\text { F 5'-TATGGAAGAGTGCTCACAACTATA-3' } \\
\text { R 5'-TCTCATGCCACCATTCAGAGGTAA-3' }\end{array}$ & $\begin{array}{l}239(.02) ; 241(.15) ; 243(.06) ; \\
245(.10) ; 247(.62) ; 249(.03) ; \\
251(.02) \ddagger\end{array}$ & 60 \\
\hline CTSC-3' & $114813-115158$ & $347-381$ & $\begin{array}{l}\text { F 5'-CTAAACTCAGGCCCTTCATCATTC-3' } \\
\text { R 5'-ACCCCTCATAAGCCCTTCTCTATC-3'† }\end{array}$ & $\begin{array}{l}347(.43) ; 353(.02) ; 355(.01) ; \\
361(.02) ; 363(.24) ; 365(.06) ; \\
367(.02) ; 369(.05) ; 371(.04) ; \\
373(.10) ; 381(.01) \ddagger\end{array}$ & 58 \\
\hline CTSC-02 & $165674-165835$ & $148-168$ & $\begin{array}{l}\text { F 5'-TAGCAGAGAAGAAGCAAGATGTGT-3' } \\
\text { R 5'-AAGCTGGACAAGGAGACTGTATAG-3'† }\end{array}$ & $\begin{array}{l}148(.04) ; 150(.03) ; 152(.04) ; \\
154(.28) ; 156(.05) ; 158(.06) ; \\
160(.25) ; 162(.07) ; 164(.15) ; \\
166(.02) ; 168(.01) \ddagger\end{array}$ & 58 \\
\hline CTSC-03 & $171820-172020$ & $193-213$ & $\begin{array}{l}\text { F 5'-CTCCCTATCCATTCTCAGTATCTA-3' } \\
\text { R 5'-CCAGAGTCACAGCAAATCTCAGAG-3' }\end{array}$ & $\begin{array}{l}193(.05) ; 195(.17) ; 197(.22) ; \\
199(.09) ; 201(.18) ; 203(.11) ; \\
205(.12) ; 207(.02) ; 209(.03) ; \\
213(.01) \ddagger\end{array}$ & 58 \\
\hline D11S1887M & 93 & $237-257$ & $\begin{array}{l}\text { F 5'-CAGGCTTCAAAGGCTTAATGTGAA-3' } \\
\text { R 5'-CCTACCTGCAACATGAGATGAGTG-3'† }\end{array}$ & $\begin{array}{l}237(.33) ; 239(.15) ; 241(.11) ; \\
243(.11) ; 245(.07) ; 249(.04) ; \\
251(.04) ; 253(.11) ; 257(.04) \S\end{array}$ & 58 \\
\hline D11S1780M & 94.6 & $263-289$ & $\begin{array}{l}\text { F 5'-TTCAGGGATCTGCAGCAATTACTT-3' } \\
\text { R 5'-TCTGAGATTACAGGCGTGAGTCAC-3'† }\end{array}$ & $\begin{array}{l}263(.04) ; 271(.28) ; 273(.14) ; \\
275(.04) ; 281(.32) ; 287(.04) ; \\
289(.14)\end{array}$ & 58 \\
\hline D11S1367M & $95-96$ & $229-254$ & $\begin{array}{l}\text { F 5'-TTAAATCTTGGTAGCCAGAACTAT-3'† } \\
\text { R 5'-ATTGTGCTAGGCTCTCTAAATACA-3' }\end{array}$ & $\begin{array}{l}221(.03) ; 229(.20) ; 233(.26) ; \\
237(.10) ; 241(.17) ; 245(0.10) ; \\
249(.07) ; 253(.07)^{\star \star}\end{array}$ & 58 \\
\hline D11S1358M & 96.3 & $273-283$ & $\begin{array}{l}\text { F 5'-AGCTCAAGTGCCTGTCAACAGATG-3' } † \\
\text { R 5'-TGCGATTCTCCTGGCTCTTAGAAC-3' }\end{array}$ & $\begin{array}{l}273(.21) ; 275(.04) ; 277(.13) \\
279(.33) ; 281(.25) ; 283(.04)+\dagger\end{array}$ & 58 \\
\hline
\end{tabular}

*The location of the CTSC specific marker is based on the BAC contig spanning the cathepsin C gene (fig 2). For the modified (M) D11S markers, the cM location is the distance from the telomeric end of the short arm on chromosome 11 based on GB4 map (www.ncbi.nlm.nih.gov/genemap99) and the physical map of 30000 human genes. ${ }^{20}$

†Location of the fluorescent label for each primer set.

$\ddagger$ Based on 112 chromosomes of Turkish controls.

$\$ \star \star \star+十$ Based on the PLS patients in this study. The founder effects of each haplotype were taken in consideration with these patients based on $25,22,30$, and 24 chromosomes, respectively. $\mathrm{T}_{\text {an }}$ : annealing temperature for PCR.

primers and annealing temperatures used to amplify these polymorphic loci (D11S1887M, D11S1780M, D11S1367M, and D11S1358M) are shown in table 1.

Results of the haplotype analysis for the 27 PLS probands are shown in table 2. Although all of the newly identified STRPs from the CTSC contig were highly polymorphic in the control population with a minimum of seven alleles detected for each locus, not all markers were equally useful for haplotype analysis. The relatively high frequency of specific alleles for several markers (CTSC-01, CTSC-int3, and CTSC-02) potentially limits their use in drawing inferences in some cases. Nonetheless, the composite haplotype data are compelling and are consistent with a shared haplotype for the four Saudi probands with the R272P mutation. These subjects are each homozygous at seven syntenic STRPs from D11S1887 to CTSC-02 (bold in table 2). These four subjects (x766, $\mathrm{x} 767, \mathrm{x} 769$, and $\mathrm{x} 770$ ) all share the same genetic haplotype for the interval spanning the CTSC gene. This haplotype was not present in the Saudi proband (x768) with the novel exon 7 G300D mutation, suggesting that this haplotype is not simply a highly conserved haplotype in the Saudi population. A Turkish proband (x235) with an R272P mutation shares the same allele at the flanking $5^{\prime}$ marker in CTSC intron 3 (CTSC-int3). This allele occurred with a frequency of $15 \%$ in the Turkish control population. With these data, we cannot determine if subject $\mathrm{x} 235$ shares a common haplotype with the Saudi patients or if the haplotype similarity represents the serendipitous sharing of common alleles.

Haplotype analyses are consistent with a common founder for three other cathepsin C mutations. The W429X mutation is shared by three Turkish probands, who are all homozygous for alleles at six loci spanning the cathepsin C gene (CTSC-01 to CTSC-03), consistent with inheritance of the W429X mutation from a common ancestor. Two Turkish probands share the same Q286X mutation, and these subjects are both homozygous for alleles at 11 loci spanning the cathepsin $\mathrm{C}$ gene locus. These findings are supportive of inheritance of the Q286X mutation identical by descent from a common ancestor. Two probands with T153I mutations were studied. $\mathrm{X} 914$, an ethnic Turk, is homozygous for the mutation. The other ( $\mathrm{p}-\mathrm{T})$, of Scottish and Chinese heritage, is a compound heterozygote with the T153I mutation and an exon 2 deletion (nt199-222 deletion resulting in deletion of amino acids 67-74, table 2). Based on haplotype data for the parents of this subject, we can determine the haplotypes transmitted with each mutation. The T153I mutation carried by subject p-T appears as part of a four locus haplotype shared with $\mathrm{x} 914$. This shared haplotype (CSTC-5' - CSTC-02) spans the cathepsin $\mathrm{C}$ gene. Although these patients are reported to be of diverse ethnic background, the shared cathepsin C haplotype is consistent with inheritance of the T153I mutation identi- 


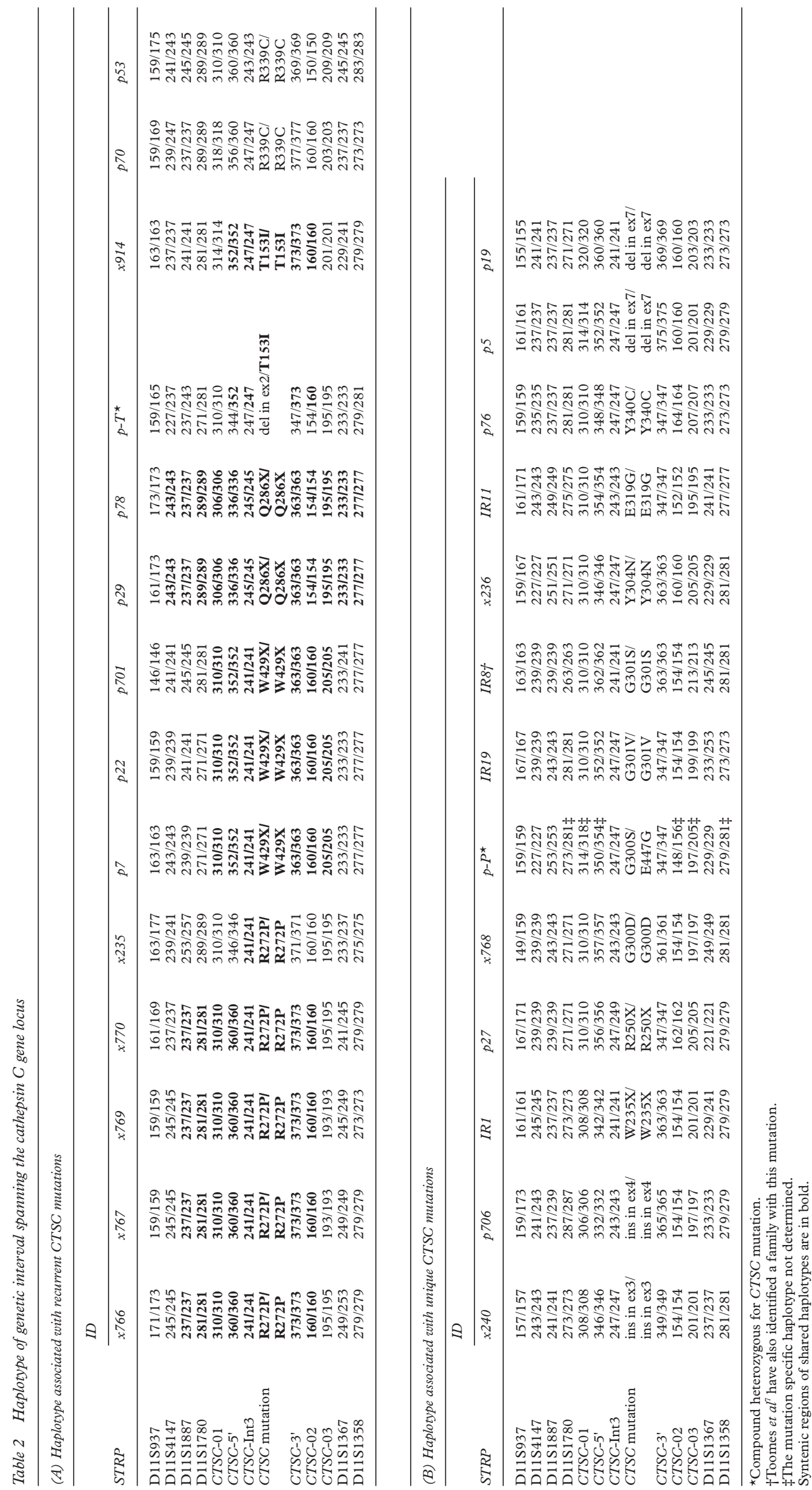


cal by descent from a common ancestor. In addition to the above shared mutations, one Turkish (p70) and one Egyptian (p53) proband are homozygous for the same R339C mutation without evidence to support inheritance from a common ancestor (table 2).

\section{Discussion}

Before this study, 25 different cathepsin C gene mutations had been reported in probands of PLS and related conditions from 32 reportedly unrelated families. While the majority of these CTSC mutations were reported in nuclear families or small kindreds, seven mutations were reported in two or more families that were not known to be related. ${ }^{78}$ To determine if any of these mutations have been inherited from a common ancestor, or if they have arisen independently, we performed haplotype studies. A difficulty in this approach stemmed from the lack of a contiguous DNA sequence for the interval spanning the cathepsin $\mathrm{C}$ gene and polymorphic DNA markers used to establish linkage. To overcome this problem, we developed a BAC contig that contains the cathepsin $\mathrm{C}$ gene locus, and identified six new short tandem repeat polymorphisms that localise to this contig. Haplotyping of 27 PLS probands has provided evidence that four of the five CTSC mutations identified in more than one family, R272P, Q286X, W429X, and T153I, appear to have been inherited from a common ancestor in the families we studied. These findings suggest that the cathepsin $\mathrm{C}$ gene is not more prone to any specific mutation in the cases studied. The availability of these six new short tandem repeat polymorphisms spanning the cathepsin C gene should permit haplotype analyses in other PLS families to identify additional cases of CTSC mutations inherited from common ancestors.

These studies were supported in part by National Institutes of Dental and Craniofacial Research R01-DE12920. The authors for critical review of this manuscript.

1 Papillon MM, Lefèvre P. Deux cas de keratodermie palmaire et plantaire symetrique familiale (maladie de Meleda) chez le frere et la soeur. Coexistence dans les deus cas d'alterations dentaires graves. Bull Soc Fr Dermatol Syphilis 1924;31:82-7.

2 Stevens HP, Kelsell DP, Bryant SP, Bishop DT, Spurr NK, Weissenbach J, Marger D, Marger RS, Leigh IM. Linkage Weissenbach J, Mar of an American pedigee with palmoplantar keratoderma and malignancy (palmoplantar ectodermal dysplasia type III) to 17q24. Literature survey and proposed updated Classification of the keratodermas. Arch Dermatol 1996;132

Online Mendelian Inheritance in Man, OMIM (TM). Johns Hopkins University, Baltimore, MD. MIM Number:
\{MIM 245000\}: \{7/27/00\}: World Wide Web URL: http:// www ncbinlm nih gov/omim

4 Gorlin, RJ, Sedano H, Anderson VERJ. The syndrome of palmar-plantar hyperkeratosis and premature periodontal destruction of the teeth. F Pediatr 1964;65:895-908.

5 Haneke E, The Papillon-Lefevre syndrome: keratosis palmoplantaris with periodontopathy. Report of a case and review of the cases in the literature. Hum Genet 1979:51:135.

6 Hart TC, Hart PS, Bowden D, Michalec MD, Callison S, Walker S, Zhang Y, Firatli E. Mutations of the cathepsin C gene are responsible for Papillon-Lefèvre syndrome. $\mathcal{F} \mathrm{Med}$ Genet 1999;36:881-7.

7 Toomes C, James J, Wood AJ, Wu CL, McCormick D, Lench N, Hewitt C, Moynihan L, Roberts E, Woods CG, Markham A, Wong M, Widmer R, Ghaffar KA, Pemberton M, Hussein IR, Temtamy SA, Davies R, Read AP, Sloan P, Dixon MJ, Thakker NS. Loss of function mutations in the cathepsin $\mathrm{C}$ gene result in periodontal disease and palmoplantar keratosis. Nat Genet 1999;23:421-4.

8 Hart PS, Zhang Y, Firatli E, Uygur C, Lotfazar M, Michalec MD, Marks JJ, Lu X, Coates BJ, Seow WK, Marshall R, Williams D, Reed JB, Wright JT, Hart TC. Identification of cathepsin C mutations in ethnically diverse PapillonLefèvre syndrome patients. F Med Genet 2000;37:927-32.

9 Pareek SS, Al-Aska AK. Papillon-Lefevre syndrome. A report of six cases in one family. Int $\mathcal{f}$ Dermatol 1986;25:638-41

10 Adbulwassie H, Dhanrajani PJ, Jiffry A. Papillon-Lefevre syndrome. Reappraisal of etiology, clinical features and treatment. II. Oral rehabilitation using osseointegrated implants. Indian f Dent Res 1996;7:63-70.

11 Lundgren $\mathrm{T}$, Twetman S, Johansson I, Crossner CG, Birkhed D. Saliva composition in children and young adults with Papillon-Lefevre syndrome. $f$ Clin Peridontol 1996;23:1068-72.

12 Lundgren T, Crossner CG, Twetman S, Ullbro C. Systemic retinoid medication and periodontal health in patients with Papillon-Lefevre syndrome. F Clin Periodontol 1996;23: 176-9.

13 Lundgren T, Renvert S, Papapanou PN, Dahlen G. Subgingival microbial profile of Papillon-Lefevre patients assessed by DNA-probes. F Clin Periodontol 1998;8:624-9.

14 Zhang J, Madden TL. PowerBLAST. A new network BLAST application for interactive or automated sequence analysis and annotation. Genome Res 1997;7:649-56.

15 Fischer J, Blanchet-Bardon C, Prud'homme JF, Pavek S, Steijlen PM, Dubertret L, Weissenbach J. Mapping of Papillon-Lefevre syndrome to the chromosome $11 \mathrm{q} 4$ region. Eur F Hum Genet 1997;5:156-60.

16 Laass MW, Hennies HC, Preis S, Stevens HP, Jung M, Leigh IM, Wienker TF, Reis A. Localization of a gene for Papillon-Lefevre syndrome to chromosome 11q14-q21 by homozygosity mapping. Hum Genet 1997;101:376-82.

17 Hart TC, Bowden DW, Ghaffar KA, Wang W, Cutler CW, Cebeci I, Efeoglu A, Firatli E. Sublocalization of the Papillon-Lefevre syndrome locus on 11q14-q21. Am $\mathcal{F}$ Med Genet 1998;79:134-9.

8 Hart TC, Walker SJ, Bowden DW, Hart PS, Callison SA, Bobby PL, Firatli E. An integrated physical and genetic map of the PLS locus interval on chromosome 11q14. Mamm Genome 2000;11:243-6.

19 Benson G. Tandem repeats finder: a program to analyze DNA sequences. Nucleic Acids Res 1999;27:573-80.

20 Deloukas P, Schuler GD, Gyapay G, Beasley EM, Soderlund C, Rodriguez-Tome P, Hui L, Matise TC, McKusick KB, Beckmann JS, Bentolila S, Bihoreau MT, Birren BB, Browne J, Browne A, Butler A, Castle AB, Chiannilkulchai N, Clee C, Day PJR, Dehejia A, Dibling T, Drouot N, Duprat S, Fizames C, Fox S, Gelling S, Green L, Harrison P, Hocking R, Holloway E, Hunt S, Keil S, Lijnzaad P, Louis-Dit-Sully C, Ma J, Mendis A, Miller J, Morissette J, Muselet D, Nusbaum HC, Peck A, Rozen S, Simon D, Slonim DK, Staples R, Stein LD, Stewart EA, Suchard MA, Thangarajah T, Vega-Czarny N, Webber C, Wu X, Hudson I, Auffray C, Nomura N, Sikela JM, Polymeropoulos MH, James R, Lander ES, Hudson TJ, Polymeropoulos MH, James R, Lander ES, Hudson TJ, DR. A physical map of 30,000 human genes. Science 1998; 282:744-6. 